\title{
CUIDAR, MORTE E MORRER: SIGNIFICAÇÕES PARA PROFISSIONAIS DE ENFERMAGEM
}

\author{
TAKING CARE, DEATH AND DYING: SIGNIFICATIONS FOR \\ NURSING WORKERS
}

\author{
Antonio Lucieudo Lourenço da SILVA ${ }^{1}$ \\ Erasmo Miessa RUIZ²
}

\begin{abstract}
RESUMO
O presente trabalho objetivou compreender as significações dos profissionais de saúde que lidam com pacientes graves acerca da morte. Utilizamo-nos da Etnometodologia, a qual nos possibilitou observar, interagir com o grupo e entrevistá-lo a fim de compreender o fenômeno. O grupo investigado constituiu-se de 10 profissionais de enfermagem lotados na sala de ressuscitação de um hospital de referência de Fortaleza, especializado em atendimento a pacientes politraumatizados. Denotamos que a morte no hospital é um fato de multienfoques e, sobretudo, negado de várias maneiras. O despreparo tanatológico produz uma série de reações nos profissionais, os quais tendem a significar a morte e o morrer, a partir das condições de trabalho, das relações de poder, envolvendo aspectos políticos, éticos, culturais e socioeconômicos. Percebe-se necessária a expansão do conteúdo tanático em âmbito acadêmico e profissional como meio de otimizar a assistência e permitir o autoconhecimento.
\end{abstract}

Palavras-chave: Morte, morrer, profissionais de enfermagem

\begin{abstract}
This paper aimed understanding the health workers significations about death. For that, we used the Etnomethodology to observe, interact with

(1) Enfermeiro da Rede SARAH de Hospitais do Aparelho Locomotor/Unidade Belo Horizonte Endereço: Rua Lorena, 962, Apto. 204. Padre Eustáquio. Belo Horizonte/MG. CEP: 30730-170. E-mail:

(2) Psicólogo. Doutor em Educação pela Universidade Federal do Ceará. Docente do Departamento de Saúde Pública

Endereço: Av. Paranjana, 1700, Itaperi. Departamento de Saúde Pública. Universidade Estadual do Ceará. Fortaleza-
\end{abstract} lucieudo@bol.com.br. Fone: (0xx31) 3411 8975/3379 2957 da Universidade Estadual do Ceará. CE. CEP: 60000-000.E-mail: poiesis@uol.com.br 


\begin{abstract}
the investigated group, which was composed by ten Nursing professionals who work in an emergency/urgency unit at a relevant hospital in FortalezaCeará. Besides the interactive observation, we collected the data using interviews. The data analysis was based on daily appointments and the speech of the group. We figured out that death is a phenomenon that includes many variants, and overall, it is denied in many ways. The tanathological deficit seems to produce some reactions on the professionals, which gives death and dying a meaning based on their work environment, power relationships, and involves political, ethical, religious, social, economical and cultural aspects. We realized the necessity of spreading tanathological contents in colleges and health institutions for improving the assistence and permitting self-knowledge.
\end{abstract}

Keywords: Death, dying and nursing workers.

\section{INTRODUÇÃO}

A morte é um dos fenômenos que mais geram interrogações em toda a história do homem sobre a Terra. Filósofos, antropólogos, cientistas sociais, variados pensadores fizeram inúmeras elucubrações acerca da morte e do mistério pelo qual está envolvida. No entanto, para uma grande variedade de pessoas, a morte é encarada ainda como um acontecimento alheio, distante de nossa realidade, de nosso cotidiano agitado, violento e miserável; banalizou-se. À medida que conferimos à morte essa banalização, esquecemos de discuti-la, de conhecê-la, de melhor trabalhar conceitos e elaborar meios mais salutares de lidar com ela, por isso agimos de forma eufemística quando nos referimos àqueles que morrem. "Passou desta para melhor", "Fez a sua última viagem", "Está descansando em paz".

À guisa de mudança de ótica com o passar dos tempos, PITTA (1990) assinala que a diferença fundamental entre a forma de lidar do homem medieval e do moderno reside na dissonância do conceito de vida em que ambos os momentos apresentavam. Em tempos atuais, o homem trata do adoecer como fato natural e do morrer como fatalismo, estando tais atitudes imbuídas de "pessimismo existencial", negador da morte.
Todavia, enfrentar a morte a todo momento tornou-se missão primordial para quem trabalha na área da saúde, ainda mais devido ao avanço da ciência, das técnicas cirúrgicas, do surgimento de tecnologias que permitem o prolongamento da vida de pacientes terminais, da produção de medicamentos em larga escala.

FOUCAULT (1980) afirma que a morte se tornou uma verdade para quem cuida, principalmente para o médico que a percebeu "como uma grande ameaça sombria em que se aboliam seu saber e sua habilidade". A morte passou a assustar, a causar pânico, a ser negada também pelo profissional, que a interpreta como a negação de seu trabalho, de seu objetivo de salvar vidas.

A morte, historicamente, passando ao hospital, teve o seu negar como uma ação coletiva, social. Escondeu-se o medo, o pavor, o morto e a doença incurável. Assim, a morte escondida pareceu aliviar a vida exterior ao hospital; no entanto, deu oportunidade ao trabalhador da área de saúde de lidar com ela como parte de seu cotidiano, mesmo incompreendida e aceita com restrições, gerando angústias, ansiedade e mais negação.

SPÍNDOLA, MACEDO (1994); PITTA (1990); FOUCAULT (1980) convergem suas idéias ao argumentarem que o doente, por ser considerado improdutivo socialmente, deve ser 
excluído e o papel do hospital vem a ser a recuperação dele para que volte à sociedade produzindo.

Conforme observam MARTINS, ALVES, GODOY (1999), negar e banalizar a morte é saída efêmera ao profissional de saúde, fazendo-lhe agir isento de envolvimento emocional algum. Essa estratégia errônea confronta-o com as falhas de suas defesas, perpetuando a sua angústia não expressa.

É explicável, em algumas instâncias, o fato de estudantes e profissionais sentirem-se impotentes diante da perda de um paciente que está sendo assistido ou reanimado. Esse "fracasso" não se traduz somente como um fracasso nos cuidados empreendidos, mas como uma derrota diante da morte e da missão implícita das profissões em saúde: salvar o indivíduo, minimizar sua dor e seu sofrimento, trazê-lo à vida.

Tal interpretação remete ao fato do despreparo acadêmico, muitas vezes, se não todas, voltado à resposta voraz do mercado capitalista e absorvedor de uma mão-de-obra não pensante. $O$ enfrentamento da morte em hospitais passa por uma gama de aspectos: psicológicos, filosóficos, sociológicos, existenciais, políticos e econômicos. Muitos dramas são vislumbrados na estrutura nosocomial e nossa tendência é afastar-nos, conscientemente ou não, daquele que está tão ansioso (paciente ou alguém de sua família) quanto nós que cuidamos.

$O$ interesse em pesquisar o assunto partiu de inúmeras inquietações advindas do campo prático, ao confrontar-nos com situações de morte e morrer de pacientes. $\mathrm{O}$ distanciamento do profissional, o medo de discutir o assunto, os momentos de interação com a família e da realização dos procedimentos pós-morte foram alguns dos aspectos propulsores da atitude investigativa, partindo dos objetivos principais: conhecer como a morte e o morrer são significados por profissionais de saúde que lidam diretamente com pacientes graves; descrever as significações expressas pelos profissionais diante da morte dos pacientes e da sua própria; compreender conceitos advindos do ideário dos profissionais acerca de morte e morrer.

\section{Metodologia}

O estudo pautou-se pela Etnometodologia, fundamentada por COULON (1995), a qual apresenta especificamente alguns passos norteadores para o processo de investigação.

Como campo de investigação, selecionamos um hospital de atendimento de emergência, referência para o tratamento de politraumatizados da cidade de Fortaleza- Ceará. O setor foi definido como a sala de ressuscitação deste hospital.

O grupo investigado constituiu-se de 7 auxiliares de enfermagem, dos quais apenas 2 eram do sexo masculino, além de 3 enfermeiras, todos lotados no setor já mencionado. Grande parte dos profissionais tem, em média, 5 anos de trabalho em atendimento de emergência e em UTI. A faixa etária oscila de 25 a 45 anos, sendo a idade média 32 anos.

De acordo com o estudo etnometodológico, utilizamo-nos da seqüência peculiar para esse tipo de enfoque. Assim, fizemos uso inicial da observação participante e da interação com o grupo a ser abordado em seu próprio ambiente de trabalho. A partir disso, realizamos apontamentos em diário de campo, os quais nos embasaram para a formulação de um roteiro de entrevistas.

As entrevistas realizaram-se em um consultório do hospital durante alguns intervalos de trabalho dos profissionais. Todos os participantes concordaram em gravar seus depoimentos, sendo-lhes garantido o sigilo sobre sua identificação pessoal e da instituição.

A análise dos discursos dos sujeitos teve caráter descritivo, tendo como referencial 
a análise de conteúdo, preconizada por MINAYO (1992). Assim baseados, reunimos trechos das falas dos participantes da pesquisa, categorizando-os segundo a similitude de seus conteúdos sugeridos nas entrevistas.

\section{Análise e discussão dos resultados}

Atendendo à garantia do sigilo das identidades dos entrevistados, utilizamos, para a apresentação de trechos dos depoimentos, nomes fictícios provenientes da cultura grega. Para as cinco auxiliares de enfermagem, usamos os nomes: Nereida, Eurídice, Jocasta, Dejanira e Penélope. Os participantes do sexo masculino são denominados de Eristeu e Hipólito. Por sua vez, as enfermeiras são tratadas por Helena, Cassandra e Ifigênia.

- O trabalho na sala de ressuscitação

\section{Estresse profissional e as condições dificeis de trabalho}

- "De certa forma, é um trabalho muito, mas muito desgastante, porque você lida diretamente com o paciente, você lida diretamente com a morte, porque o nome já tá dizendo: Ressuscitação, né. $E$ naquela sala ali, raríssimas, pouquíssimas pessoas saem com vida daquela sala." (Nereida)

- "É deprimente pelos pacientes, pela pouca área, a estrutura, os aparelhos, não tem como atender bem e além disso a demanda." (Dejanira)

- "Porque, por mais que você tenha um profissionalismo, você é gente, você sente, se desgasta com aquilo, você vê aquela pessoa morrer, morrer, sem poder fazer nada, sem fazerem nada, né, muitas vezes. (...) Eu nunca me esqueci o dia que morreram oito numa tarde só, nesse dia, eu fui pra casa arrasada, arrasada." (Penélope )
Como arrolados pelos entrevistados, a lida com o paciente grave, a falta de recursos materiais mínimos, a superlotação da sala e o desvio funcional da mesma podem remeter à grande demanda que adentra a sala como fator primário. Trabalhar sob condições insalubres, desgastantes, em que o atendimento preconizado não é realizado, apenas esboçado, é uma contingência de grande relevância para a contextualização do psiquismo do profissional e a operacionalização de seus cuidados.

PITTA (1990) suporta que o regime de turnos e plantões, as jornadas múltiplas de trabalho em diferentes serviços, o contato intermitente com doentes gravemente acometidos, o acúmulo de atividades desagradáveis que esse contato pode gerar potencializam danos físicos e psíquicos ao indivíduo.

Se as organizações hospitalares não reconhecem a existência do psiquismo de seus trabalhadores, se elas não preconizam a construção de projetos psicossociais de intervenção sobre as demandas impostas pelas rotinas e plantões, o profissional não encontra no próprio espaço laboral uma válvula de escape para frustrações e dificuldades do dia-a-dia. A construção da desafetivação da pessoa sob o risco de morte pode expressar não uma insensibilidade livremente escolhida mas, antes de tudo, a única possibilidade existente para resguardar-se do sofrimento psicológico que a própria atividade lhe impõe.

\section{O "descaso médico"}

- "O que eu acho mais difícil lá é essa relação com o médico. Porque não fica lá um tempo inteiro, às vezes, você necessita, aí você chama e dificilmente ele vem na hora que você chama." (Eurídice)

- "...e quando chega na ressuscitação, os médicos esquecem, acham que tá na ressuscitação e não tem jeito." (Hipólito) 
- "Eu tava cansada de ver paciente grave, gravíssimo, chorando, implorando por um respirador e o médico, simplesmente, sentava e dizia: 'Pra que, minha filha? Vai já morrer, deixe morrer."' (Nereida)

$\mathrm{Na}$ sala de ressuscitação não trabalha um médico com escala fixa no local, e tal fato repercute na assistência ao paciente grave que, muitas vezes, morre sem ser atendido ou avaliado por um médico, segundo os próprios entrevistados. A desumanização do serviço médico, embora tenha sido constatada em observações a priori, é um dado percebido e corroborado pelos depoimentos.

O saber médico, ainda imbuído da hegemonia do cientificismo, da afinidade com a tecnocracia, de uma obsoleta ótica clínica medieval contribui para o reducionismo do significado da morte. Qualquer exercício que foque a culpabilizacão dos indivíduos pela disseminação destes saberes e práticas será sempre restrito. Como nos alerta Foucault, temos que pensar no saber médico como um modo de produção de verdades. Uma das "verdades" produzidas diz respeito à dessacralização da morte e do morrer, o que implica que este saber que intenta regular estes processos retira daqueles que deles participam diretamente (os moribundos) a capacidade de regular e/ou intervir na própria experiência.

\section{Discriminação e pré-julgamentos}

- “... paciente que tenta suicídio, tem muita gente que diz: 'Olha, uma desgraça dessa, porque é que não morre? Bem feito, bem feito, é pra sofrer mesmo.' (...) 'Por que não morreu na hora, vem dar trabalho aqui?' " (Jocasta)

- "... se ele é que procurou a morte, problema dele. (...) Eu já preparo assim: 'Ah, ele que procurou isso, então, ele que quis.' " (Cassandra)
- "Principalmente, o paciente com HIV. (...) Nós mesmos, temos relato, já vimos colegas que não quer fazer, dar um banho no leito, porque têm medo de pegar." (Eristeu)

- "Eles acham assim: 'Não, ele já tá com morte cerebral, pronto, deixa pra lá.' Pra começar do médico." (Penélope)

- "Você vê o paciente de AVC, idoso, sofrendo tanto ( ...) você não se envolve tanto. Não tem grandes chances de recuperação, enquanto você vê um paciente jovem, (...) se envolve numa vaga de $\mathrm{UTI}$, tentando conseguir aquela vaga, porque sabe que ele vai se recuperar." (Eurídice)

O suicida, em especial o intoxicado exogenamente, o paciente soropositivo para HIV e aquele com morte cerebral tendem a sofrer uma série de pré-julgamentos, desde seu momento de chegada até sua alta ou óbito. A discriminação coexiste com o atendimento de múltiplos profissionais da área. Evidente que essa postura preconceituosa não é mantida por todos os indivíduos. No entanto, na maioria dos casos ela ocorre e a justificativa empregada para o fato é a grande demanda que "sufoca", "asfixia" o profissional.

O cuidado especial com pacientes mais jovens e o apego maior a eles são fatos observados na prática lembrados pelas entrevistas, como no trecho anterior. Parece "normal" pensar que a morte de uma pessoa mais velha, exemplificando-se, com acidente vascular cerebral ou outro diagnóstico crônico degenerativo até mesmo vítima da violência urbana, seja um fato mais aceitável e salutar de se lidar. Quando o quadro envolve pessoas jovens, a presteza e a especificidade do cuidado do profissional surgem com maior freqüência.

- A notícia da morte para a família

\section{Uma difícil tarefa}

-“ ...você lida muito com família e, geralmente, paciente grave, com morte 
cerebral. ( ...) É muito difícil fazer um membro da família entender. Muito difícil. Por isso a gente se desgasta." (Nereida)

- "Eu acho terrível, eu detesto, se tiver que fazer, eu faço com muita dó, não combina comigo." (Eurídice)

- "É muito triste. Ah, me deu um mal-estar tão grande, uma coisa tão ruim. É ruim. É muito difícil, muito difícil." (Jocasta)

- "... é triste porque eles choram, a gente chora, eu choro. Eu choro muito, porque eu vejo a dor de um pai, de uma mãe, de um irmão, em cima daquela pessoa, próximo ao cadáver." (Dejanira)

- "A gente vivencia a morte, mas compartilhar aquele sentimento de perda mesmo, ninguém quer." (Eristeu)

É inconteste o fato de que o profissional em saúde, ao informar alguém da morte de parentes e amigos em situações quaisquer, confronta-se de modo inevitável com as suas próprias convicções, anseios e significação da morte. Admitir a morte como um fato na profissão, repassá-la aos outros como um "fracasso" ou falta de êxito nas manobras de reanimação, é algo frustrante e causador de ansiedade.

PITTA (1990) aventa a justificativa de que o medo e o adiamento de avisar a família da morte do doente ou de sua proximidade assemelha-se ao medo do profissional, que ao se deparar com sentimentos e reações "descontrolados", também teme perder o controle sobre suas reações emocionais.

Os eufemismos utilizados, a história parabólica dita aos familiares permitem-nos imaginar um possível meio de dirimir a dor de quem recebe a notícia. Não seria presunçoso cogitar que o profissional age desse modo, baseado em uma atitude empática, espelhando-se em si, em sua vivência não-profissional, em seu conjunto de sentidos e interpretações acerca de um contexto tanatológico.
- A transferência para a UTI

- "Existe uma escolha, sim. Se for idoso, esse é o último." (Jocasta)

- "Critério médico, só ele quem decide. Você tem que ter QI, quem indique. Parente de médico, amigo de médico, conhecido de médico, outro não." (Eristeu)

- "É o seguinte: o dinheiro manda (...) o dinheiro é o parentesco, se é uma pessoa pobre, não tem vaga. Mas se a pessoa é provida de uma situação financeira boa, então tem vaga." (Cassandra)

Tende-se a concluir que existe um processo de escolha nítido de pacientes a serem transferidos para leito de UTI. Este processo tem uma conformação própria desenhada, principalmente, pela hegemonia médica. Segundo a exposição dos profissionais investigados, o critério médico é o poder decisório e, baseado nele, seguem-se as variedades de pacientes a serem selecionados. Citamos os casos e critérios lembrados: a oportunidade é dada àqueles cujo prognóstico é bom, oferecendo condições significativas de recuperação; os pacientes jovens são preferidos em comparação aos mais velhos; paciente que tem vínculo afetivo e familiar com profissionais médicos ou que detenha certa influência ou conhecimento de alguém do setor.

- O preparo do corpo após a morte

\section{Sensação deprimente e adaptação natural}

- "No começo, eu me sentia mal, eu não gostava de fazer pacote. Porque achava esse nome pacote, embrulho muito pesado. (...) Eu sentia muito deprimida." (Nereida)

- "Eu sempre fui uma pessoa medrosa pra paciente que morria, sempre tive medo. (...) Mas é o dia-a-dia, a gente não pode ficar com a tristeza de todo 
mundo, é o serviço da gente. Aí a gente encara como normal mesmo..." (Hipólito)

\section{Falta de respeito com o corpo}

- "Uns cuidam com respeito, outros fazem por fazer como se tratasse de objeto, porque tem outro mais grave que tá vivo e aquele não tem mais que se preocupar com ele." (Dejanira)

- "Tem dia que você vai preparar aquele corpo com a maior simplicidade do mundo, cruza aqueles braços do paciente, coloca assim uma atadura, na própria higienização, aí, às vezes, você até brinca com algumas coisas." (Cassandra)

A fuga estratégica do preparo do corpo pode ser explicada, em termos, por um prisma de cunho psicanalítico, podendo significar o medo de encarar a morte, a própria finitude. Deparar-se com o corpo morto é negar a vida, há pouco perdida, assim como a do próprio profissional lato sensu envolvido com o procedimento. Parece não ser salutar, agradável aos olhos, aos sentidos manipular um cadáver, enxugar e limpar seu corpo úmido de secreções, tamponar com algodão seus orificios antes intactos. É um confronto com a morte, é a negação da vida, é a perda de um paciente, é a negação da profissão, das ações antes empregadas, dos cuidados prestados, é o "desafio perdido".

Realizar o procedimento é 'constrangedor', é 'lamentável', é 'triste'; deparamo-nos com a impotência diante da inexorabilidade da morte. Não está nos livros, nas aulas, nas discussões que a morte e o morrer estarão presentes na prática em uma dimensão mais ampla, apenas as técnicas reduzem o fato a um procedimento como muitos outros.

Parece ser tendência lógica adaptar-se à situação como rotina, agir mediante uma postura mais isenta de "sentimentalismo" e envolver-se apenas "profissionalmente", após o passar dos anos de prática. Ademais, quando a perda de pacientes é uma constante, o profissional, na maioria das vezes, não mais se "assusta" como antes ou se sente frustrado ou perturbado; pelo menos, consegue esconder, mascarar suas reações em tomo, algumas vezes, de seu silêncio.

- A morte

\section{Uma passagem, desígnio de Deus e renascimento}

- "Uma passagem, uma passagem. Se eu te falo do lado religioso, é uma passagem, porque aqui essa vida pra gente é uma vida passageira." (Nereida)

- "A morte? Acho que ela é o final de uma etapa, uma etapa que eu tô cumprindo agora aqui. Minha passagem é essa, meu tempo agora é esse, morreu, acabou meu tempo, tempo esgotado ..." (Jocasta)

Refletindo sobre, deduz-se que a morte é interpretada sob um prisma religioso muito forte e significativo. A crença na continuidade da existência por meio de uma passagem para um plano metafisico ou o término da temporalidade terrena advém de uma cultura arraigada às civilizações antigas.

A religião, nesse sentido, parece funcionar como um ansiolítico diante da morte e do morrer. Torna a morte um fato, de certa maneira, mais aceitável, porque "inteligível" e, portanto, "explicável". Ater-se à idéia de um porvir paradisíaco alenta os indivíduos perante a irrefutabilidade da morte e de seu mistério cunhado pelas culturas, em especial as ocidentais, como amedrontador e desamparador.

\section{O fim e a tristeza}

- "A morte... A morte é o fim de tudo, o fim assim, da matéria, porque eu acho que tem outra vida do lado de lá." (Penélope) 
- "A morte é o fim de tudo, é triste, porque você deixou pra trás tudo que trabalhou, pensou, construiu, realizou, muitas vezes, nem dá tempo de realizar algum sonho." (Hipólito)

É notório o constrangimento e a dificuldade do profissional em falar sobre o assunto. Entretanto, as pausas em seu discurso, os suspiros, a voz embargada, a mudança de olhar com relação ao entrevistador expressam plausivelmente a insatisfação diante do inexorável. Constrói-se uma abstração da morte e do morrer concreto do outro. Assumir a morte concreta do indivíduo assistido significa compartilhar da realidade trágica e dolorosa do sentimento da perda de si mesmo.

- A morte e o cuidado com o paciente grave

\section{Tristeza, sofrimento, apego e impotência}

- "Eu sentia muita deprimida. Aliás, eu ficava muito triste, eu não gostava quando morria paciente no meu plantão." (Nereida)

- "...tem casos que você chega a chorar junto com a família ( ...) você chega mesmo e diz: 'Já pensou se fosse da família minha?' Aí você chega a chorar junto com a família." (Cassandra)

- "É assim, dá uma impressão de impotência. Você não poder fazer nada pra tentar resgatar aquela vida de volta." (Jocasta)

Perder um paciente, como exposto por alguns profissionais, é condição de impotência, tristeza, pena, de dificuldade. Impotência, em virtude da inexorabilidade da morte, tristeza e pena, diante da perda de uma vida humana, a qual dependia de seus cuidados, além da forma violenta que levou à morte e os casos em que o envolvimento emocional parece inevitável. A dificuldade sentida por não saber lidar com o processo de morte e morrer.
Como expõem SPÍNDOLA E MACEDO (1994), participar do morrer dos pacientes desencadeia naquele que os assiste uma série de sensações, como a perda, a impotência e a depressão, as quais estão vinculadas a um despreparo formativo em que morte e morrer não são transmitidas como circunstâncias presentes no cotidiano de quem lida com vidas, salvando-as ou preservando-as.

\section{Lidar profissionalmente como um fato "comum"}

- “... na minha percepção, você fica muito fria, você lida com a morte como se não fosse nada, você chega num estágio da vida que você prepara o corpo, prepara o pós-morte como se não fosse nada." (Cassandra)

- "Se torna, apesar de tratar de vida, uma coisa comum." (Dejanira)

Deparamo-nos, em outro turno, com a conduta mantenedora de um litígio do profissional com o próprio campo de suas emoções e sentimentos ao lidar com o paciente e sua morte iminente ou consumada. A adaptação à situação corriqueira parece deixar o profissional menos sensível às perdas cotidianas de indivíduos assistidos por ele. A aceitação como estágio do morrer pode ser evidenciada nesse sentido.

SPÍNDOLA e MACEDO (1994) dão um tom à questão, quando afirmam que a insensibilidade aparente do profissional, ao vivenciar mais uma perda, significa um mecanismo de defesa utilizado com o fim de "suportar" a situação cotidianamente.

\section{Despreparo para a morte}

- "Nós ainda não entendemos a morte, nós ainda não aceitamos a morte, que é diferente a morte de um familiar e a morte de uma outra pessoa, mas às vezes, em certos momentos, a gente 
quer identificar como se fosse com a gente." (Cassandra)

- "Eu acho que a gente tinha que se preparar pra ela, não pensar muito só na gente, pensar no outro também, que tá do lado da gente." (Jocasta)

Nos discursos anteriores, enfatiza-se a necessidade de se aprender a lidar com a morte, estando os profissionais cientes do despreparo no convívio com o morrer e seus meandros no hospital. A urgência de interrelacionamento empático e da assistência mais ampliada é outra consideração relevante no trato com pacientes graves e moribundos referendada pela auxiliar entrevistada.

KÜBLER-ROSS (1996, p. 273) assinala que: "ser terapeuta de um paciente que agoniza é nos conscientizar da singularidade de cada indivíduo neste oceano imenso da humanidade. É uma tomada de consciência de nossa finitude, de nosso limitado tempo de vida."

Como evidenciado nas entrevistas, a conduta pesarosa e ansiosa do cuidador, suas expressões de sentimento, a angústia ou a relutância em explanar opiniões sobre o assunto, como constatado pela negação da enfermeira que negou dar a entrevista em virtude de não gostar do assunto, parecem exibir um déficit da percepção. Tal déficit que poderia ser minorado no processo educacional do indivíduo é cronificado e tende a transformar-se em medo, distanciamento e angústia com relação à morte, em níveis imensuráveis.

A formação na área de saúde fomenta, ainda em grande escala, a biomedicina com tendências ímpares e incipientes de respaldar o terapeuta com um cerne mais humanista, ético, social, voltado ao sentido mais amplo das coisas e dos fenômenos não-somáticos. Quem lida com vida, de modo indelével, lida com morte e com toda a conjuntura implícita no fato do morrer

ABDO (1992) revela que, ao se preparar alguém para a morte (o paciente), prepara-se, ao mesmo passo, a morte de quem atende, pois ao se deparar com o indivíduo que morre, o profissional poderia atuar por um viés mais empático, embora seja uma tarefa dificil.

\section{O profissional $X$ o emocional e a identificação com os casos}

-“...um fato recente que marcou muito foi um colega da gente (...) que sofreu um acidente gravíssimo (...). E a gente ter que colocar a emoção, essa coisa assim de proteção do lado e agir profissionalmente. Isso marcou muito, muito." (Nereida)

Quando a entrevistada se remete ao cuidar do próprio colega, temos ilustrativamente a prova cabal de que não há como se isentar de envolvimento, de não existir um embate de convicções, de perguntas, anseios e limites que emergem naquele instante em que se atende. Sugere a reafirmação do despreparo conjuntural para lidar com os aspectos da morte e do morrer.

Um dos grandes dilemas dos profissionais ao lidarem com o paciente grave e o morrer é definir até que ponto se deve estender o contato emocional com o paciente. Fala-se muito em manter-se a postura profissional, mas ao tentar agir o mais profissionalmente possível, o cuidador restringe a sua atuação apenas à repetição de técnicas. Para ser profissional não se deve tolher as emoções e sentimentos do indivíduo, especialmente em saúde, quando o trabalho existe entre pessoas, por meio da comunicação, da troca interativa, do expressar-se e entender o expresso em uma linguagem simbólica.

-"Eu havia cuidado dos meus pais. Digamos, você fica perdido, você sabe o que tem que fazer, você sabe o que é pra fazer, mas a tua cabeça não coordena." (Eristeu)

- "Tem uma coisa que marcou muito foi quando eu tava grávida (...) Chegou uma mulher dentro da ressuscitação. 
Ela sofreu um acidente e na hora mesmo, os médicos tiveram que tirar o menino, mas ela morreu (...) Naquela tarde, eu não consegui mais trabalhar." (Penélope)

- "Depois que eu fui mãe, eu não gostava de lidar de criança. Eu só lembro de uma criança grave que chegou (...) pela história que repassava era a mesma idade da minha filha e eu não tive estrutura nem pra receber a criança, eu não tive." (Nereida)

Revisitando os trechos anteriores, podese perceber como a história de vida tende a interferir no atendimento em saúde aos casos mais críticos. Isso não significa que qualquer profissional que se vê envolvido com uma situação, a qual se assemelha a uma condição de sua história pessoal ou a de algum parente, esteja fadado a ausentar-se da ação ou não concluí-la. Indica, todavia, que ao se deparar com sua história, ele se sente sensibilizado com o fato, o que interfere em seu psiquismo, em suas significações de trabalho, de morte e morrer.

Corroborando a premissa, SCHUR (1981, p.461) afirma o seguinte: "A avaliação da morte leva, seguramente, ela mesma, prontamente a ser vinculada a todas as situações traumáticas anteriores. A negação constante da morte, que todos nós praticamos, parece constituir comprovação a favor dessa suposição."

\section{CONSIDERAÇÕES FINAIS}

Em seu cerne, o fenômeno tanático suplanta empirismos materiais e conceituações acabadas das mais diversas origens, embora elas sejam necessárias para a compreensão de seu sentido multifacetado. A variedade contextual, o processo histórico, os princípios éticos e religiosos, as relações de poder e de mercado condensam-se em um oceano de imaginários, os quais podem complementar-se ou, dialeticamente, divergir em busca desse compreender.

A mudança do ponto de vista das pessoas acerca da vida, do viver, da morte e do morrer pode estar inter-relacionada com a mudança de preocupação, de prioridades, decorrente de uma transformação dos meios de produção e de saber. As tecnologias, as expectativas de vida aumentadas, as inovações no campo da cirurgia plástica e da nutrição dizem respeito a uma apologia constante ao corpo, ao culto ao físico, à esculturação estética e às estereotipias advindas de padrões estabelecidos com o passar das "modas" e das "diretrizes" do efêmero.

As fantasmagorias da finitude absoluta convivem, de braços dados, com as percepções da vinda de um mundo melhor post mortem e, de certa forma, reproduzem o conflito da existência humana desde épocas primordiais. Se, coincidentemente, todos os deuses são imortais e/ou ressuscitam, os homens não aceitam passivamente a condição de mortalidade e, assim, desejam ser deuses. $\mathrm{O}$ filósofo Friedrich Nietzsche, ao afirmar que "Deus está morto" em sua obra Assim falou Zaratustra, redimensionou a posição significativa de Deus e da religião para o homem, traduzindo-os como uma manifestação humana e assim, falíveis e questionáveis.

Ao investigarmos a morte à luz das significações de profissionais da saúde, em especial, os da enfermagem, vislumbramos a persistência de tal bojo contingencial que os leva a definir, conforme suas histórias e simbologias individuais, a morte e o morrer pela prática cotidiana no hospital.

Na estrutura nosocomial, a morte parece ser, sobretudo, negada. Negada pela própria condição de encarceramento tutelar dos que morrem, do ato de morrer e suas nuances. Nega-se enquanto profissionais, conduzidos por uma possível lógica adaptativa e mercantil, agem de modo indiferente, impessoal, antiético. Conquanto neguem em alguns 
momentos, afirmando tratar do assunto como "algo comum", "a perda de mais um paciente", ou "melhor preparados" em virtude dos anos de experiência, em outros, mostram-se contraditórios ao revelarem seus medos e anseios pela expressão inevitável e notória de seus lamentos, de seus fácies entristecidos, de seus silêncios, de suas lágrimas e suas fugas literais do momento da morte e dos procedimentos de cuidado ao corpo morto.

Questões éticas, políticas e sociais emergem na "jornada hospitalar", tornando a temática por demais complexa. A decisão de quem vive e quem morre em leitos de hospitais públicos do país é certamente uma realidade mascarada e tratada confidencialmente. A conduta hegemônica do médico, advinda de uma construção histórico-cutural, exibe ainda forças e produzem cicatrizes de toda natureza.

Os aspectos psicossociais e tanatológicos costumam ser preteridos nas escolas da área de saúde. Considerando a multiplicidade de aspectos tratados em nossa pesquisa e em outras afins, urge o fomento de disciplinas, grupos de estudos, seminários, centros de discussão acerca da tanatologia nas universidades e hospitais, o que seria uma estratégia de imensurável valia para o preparo dos profissionais para a morte e o morrer, inclusive em termos de autoconhecimento. Educar para a vida implica entender a morte como uma manifestação vital, como algo decorrente do viver, por mais contraditório que tal afirmação possa parecer.

Ainda que a iniciativa tenha alcançado alguns ganhos no que diz respeito à criação de disciplinas, cursos, debates, sites, fóruns de discussão e à divulgação de artigos científicos, a prática é considerada incipiente.

Ampliar o conhecimento sobre o conteúdo tanático não permitirá que o indivíduo compreenda a morte em toda a sua complexidade. Contudo, possibilitará uma melhor atitude diante dela, proporcionando um agir "profissional" mais ético, mais filosófico, mais atentivo, mais humano. Preparar-se-ão, logo, indivíduos capazes de enfrentar a morte e o morrer menos alheios a eles, podendo interpretá-los como partícipes da vida e não como sua antítese.

\section{REFERÊNCIAS}

ABDO, C. A. N. Abordagem do paciente terminal: relato de um psicodrama interno. Revista de Psiquiatria Clínica. N .15-19 (edição especial), 1996, p. 24-26.

COULON, A. Etnometodologia e educação. Petrópolis: Vozes, 1995.

Campinas: Papiros, 1995.

FOUCAULT, M. O nascimento da clínica. Rio de Janeiro: Forense-Universitário, 1980, 2 ed.

KÜBLER-ROSS, E. Sobre a morte e o morrer. São Paulo: Martins Fontes, 1998. MARTINS, E. L. AlVES, R. N. GODOY, S. A. F. Reações e sentimentos do profissional de enfermagem diante da morte. Revista Brasileira de Enfermagem. Brasília, v.52, n.1,jan/mar. 1999, p. 105-117.

MINAYO, M. C. S. Fase de análise ou Tratamento do material. In: .O desafio do conhecimento: pesquisa qualitativa em saúde. São Paulo: HUCITEC-ARRASCO, 1992, p. 197-247.

PITTA, A. M. F. Hospital: Dor e Morte como oficio. São Paulo: HUCITEC, 1991.2 ed. SCHUR, M. Freud: Vida e agonia. Rio de Janeiro: Imago, 1981, volume 2.

SPÍNDOLA, T., MACEDO, M.C.S. A morte no hospital e seu significado para os profissionais. Revista Brasileira de Enfermagem, v.47.

Recebido para publicação em 04 de fevereiro de 2002 e aceito em 23 de maio de 2002. 